مجلة العلوم الهندسية_ العدد الثالث- 2008

\title{
Design, Fabrication and Testing of Thermistor Detector
}

\author{
Abbas Babiker Ali Maruod*, Kasim M. Al-Hity**,Yahia Abdulla \\ Mohamed***, Nafie A-Latif AL-Muslet*
}

\begin{abstract}
The main idea of this work is to design and fabricate an infra-red detector, specially the disk type of negative thermistor (NTC), and to test it's operation and response to different levels of IR laser power.

The challenge of the fabrication arises from the chemical, physical and electronic thermistor features. In order to get good responsivity, a certain semiconductor oxides ratio prepared and milled with special size and shape under tones of pressure, then sintered with thousand of temperature degrees, and finally coated and attached with legs to get the thermistor. An electronic circuit, consists of some amplifiers, comparator and reference voltage, was used to test the disk thermistor operation.

Finally, different levels of Nd:YAG laser power was used to test the fabricated thermistors. The results are very promising and the best ratios of the mixture could be easily determined.

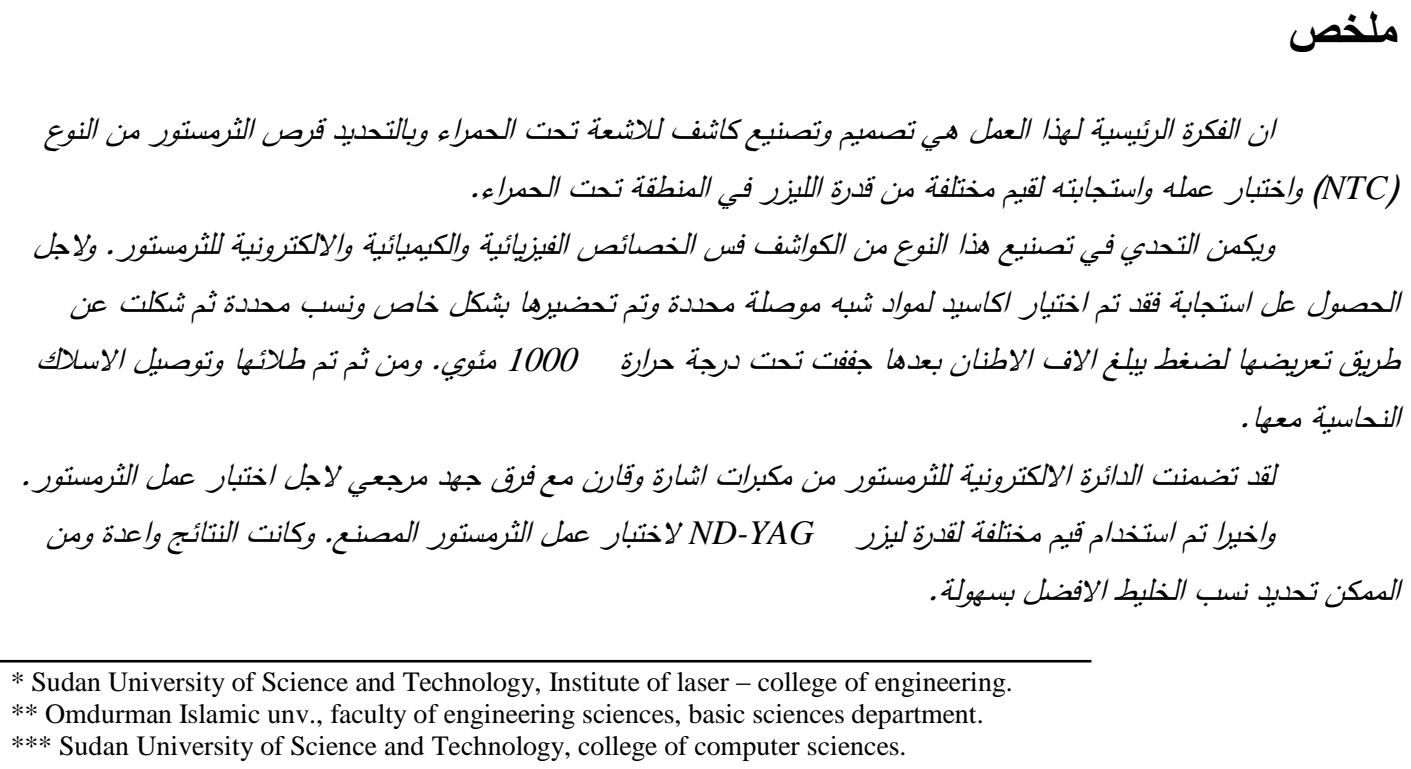

\section{Theory}


Detectors suitable for monitoring optical power or energy are commonly employed along with lasers and other light sources. For an application such as laser communication, a detector is necessary to receive the light signal. For applications involving interferometry, detectors are used to measure the position and motion of the fringes in the interference pattern. In applications involving laser material processing, a detector monitors the laser output to ensure reproducible conditions. In many applications, one desires a detector to determine the output of the laser or other light source. The detection of optical radiation is usually accomplished by converting the optical energy into an electrical signal.

Optical detectors include photon detectors, in which one photon of light energy releases one electron detected in the electronic circuitry, and thermal detectors, in which the optical energy is converted into heat, that generates an electrical signal. Often the detection of optical energy must be performed in the presence of noise sources, which interfere with the detection process. The detector circuitry usually employs a bias voltage and a load resistor in series with the detector. The incident light changes the characteristics of the detector and causes the current flowing in the circuit to be changed. The output signal is the change in voltage drop across the load resistor. Many detector circuits are designed for specific applications [1].

All optical detectors respond to the power in the optical beam, which is proportional to the square of the electric field. They are thus called "square-law detectors". Microwave detectors, in contrast, can measure the electric field intensity directly. But all the detectors that we consider here exhibit square-law response. This is also true for other common optical detectors such as the human eye and photographic film [2].

The detection and measurement of infrared radiation is a well-established area of technology. In recent years, this technology has been applied specifically to laser applications, and detectors particularly suitable for use with lasers have been developed. Commercial developments has also involved detectors, specially designed and packaged for use with lasers and marketed by numerous manufacturers. Some detectors are packaged in the format of a power or energy 
مجلة العلوم الهندسية_ العدد الثالث- 2008

meter. These devices include a complete system for measuring the output of a specific class of lasers, included detector, housing, amplification if necessary and a readout device [3].

\section{Experimental work}

The thermistor material is physically, chemically and electronically, an extremely complex system whose properties continue to defy exact description [4]. Practical production of useful thermistors depends upon a great deal of experience, adjustments in mix and fabrication. The steps of constructing disk thermistors in this work are shown in figure (1).

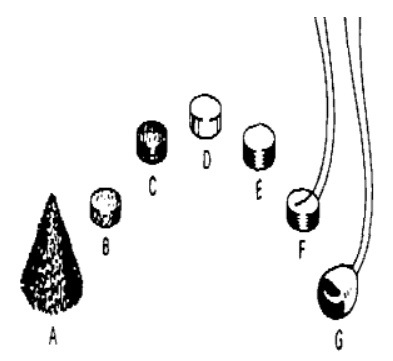

\section{Figure (1) Thermistor disk fabrication steps}

A. Powder ballmilling. B. Disk pressing. C. Disk sintering. D. Disk silvering.

E. Disk edge-grounding. F. Lead wires attaching. G. Epoxy-coating.

Five elements oxides were used with different ratios to find the optimum conditions of best thermistor fabrication. The fabricated thermistors were classified to groups according to the mixing ratios.

The following ratios were mixed to fabricate group (one):-

$$
\mathrm{Mn}_{3} \mathrm{O}_{4} \quad \mathbf{6 5 \%} \quad \mathbf{= 3 . 2 5 \mathrm { g }}
$$


Design, Fabrication and Testing of Thermistor Detector.....

Abbas Babiker

$\begin{array}{lll}\mathrm{ZnO} & \mathbf{8 \%} & \mathbf{0} \mathbf{0 . 4 0} \mathrm{g} \\ \mathrm{Fe}_{2} \mathrm{O}_{3} & 3 \% & =\mathbf{0 . 1 5} \mathrm{g} \\ \mathrm{TiO}_{2} & 12 \% & =\mathbf{0 . 6 0} \mathbf{g} \\ \mathrm{Al}_{2} \mathrm{O}_{3} & 12 \% & \mathbf{0 . 6 0} \mathbf{g}\end{array}$

While the following ratios were mixed to fabricate group (two):-

$\begin{array}{lll}\mathrm{Mn}_{3} \mathrm{O}_{4} & \mathbf{6 5 \%} & \mathbf{3} .25 \mathrm{~g} \\ \mathrm{ZnO} & \mathbf{8 \%} & \mathbf{0 . 4 0} \mathrm{g} \\ \mathrm{Fe}_{2} \mathrm{O}_{3} & 3 \% & =\mathbf{0 . 1 5} \mathrm{g} \\ \mathrm{TiO}_{2} & 19 \% & =\mathbf{0 . 9 5} \mathrm{g} \\ \mathrm{Al}_{2} \mathrm{O}_{3} & \mathbf{5 \%} & \mathbf{0 . 2 5} \mathbf{g}\end{array}$

And the following ratios were mixed to fabricate group (three):-

$\begin{array}{lll}\mathrm{Mn}_{3} \mathrm{O}_{4} & \mathbf{6 5 \%} & \mathbf{3} .25 \mathrm{~g} \\ \mathrm{ZnO} & 15 \% & =\mathbf{0 . 7 5} \mathrm{g} \\ \mathrm{Fe}_{2} \mathrm{O}_{3} & 3 \% & =\mathbf{0 . 1 5} \mathrm{g} \\ \mathrm{TiO}_{2} & 12 \% & \mathbf{0 . 6 0} \mathrm{g} \\ \mathrm{Al}_{2} \mathrm{O}_{3} & \mathbf{5 \%} & \mathbf{0 . 2 5} \mathbf{g}\end{array}$

Each group was mixed with $12 \mathrm{cc}$ distilled water, the first material was put for half an hour in magnetic stirrer and the other materials were added one after 
مجلة العلوم الهندسية_ العدد الثالث- 2008

one, then the compound was filtered by $110 \mathrm{~mm}$ type round paper filter, dried and put in furnace to drive off moisture.

Five grams of ball milled powder were took from each group to make two pressed disks samples with $2.5 \mathrm{~cm}$ in diameter and $0.55 \mathrm{~mm}$ in thickness using apress of $5-10$ tones per $\mathrm{cm} 2$.

The pressed disk samples then were put in furnace for few hours to make Sintered disk.

After that, the following three steps were done for the sintered disks:

1- Silvering each sample using conductive material.

2- Soldering the silver disk to fix the two wires.

3- Coating the sample with epoxy.

From the above processing of the disk thermistor fabrication, three types were obtained with different resistance listed in table (1).

Table (1) Thermistors resistance of the three groups

\begin{tabular}{|l|l|l|}
\hline Group no. & \multicolumn{1}{|c|}{$\begin{array}{c}\text { Resistance at fabrication } \\
\text { temperature } \mathbf{1 0 0 0}^{\circ} \mathbf{C}(\mathbf{M} \Omega)\end{array}$} & $\begin{array}{c}\text { Resistance at fabrication } \\
\text { temperature } \\
\mathbf{1 1 5 0}^{\mathbf{0}} \mathbf{C}(\mathbf{M} \Omega)\end{array}$ \\
\hline ONE & 1.7 & 1.9 \\
TWO & 3.2 & $>88$ \\
THREE & 1.6 & 3.6 \\
\hline
\end{tabular}

By incorporating the thermistor into a voltage divider, it is possible to create an output voltage that is dependent on temperature change. An electronic circuit was designed and built for measuring the output voltage. The circuit is shown in figure (2) and it consists of thermistor circuit, digital to analog converter, comparator, analog to digital converter and the ADC. The IR laser power was used to change the resistance of the fabricated thermistors, and the output voltage for each thermistor was measured.

We can use the voltage divider equation to find the voltage at the noninverting input of the op-amp. Since we are dealing with a wide range of IR radiation power, and hence voltages, it is not necessary to amplify the voltage at 
the non-inverting input, so the op-amp was set up as an $\mathrm{x} 1$ buffer, The CA358 opamp was biased with $0 \mathrm{~V}$ and $\mathrm{VCC}=5 \mathrm{~V}$. The circuit analyzing by radiating IR laser beam on the disk thermistor, or by applying VCC to the disk thermistor, and then monitoing the Resistance/Temperature curve or Resistance/Voltage curve to deduce the voltage change.

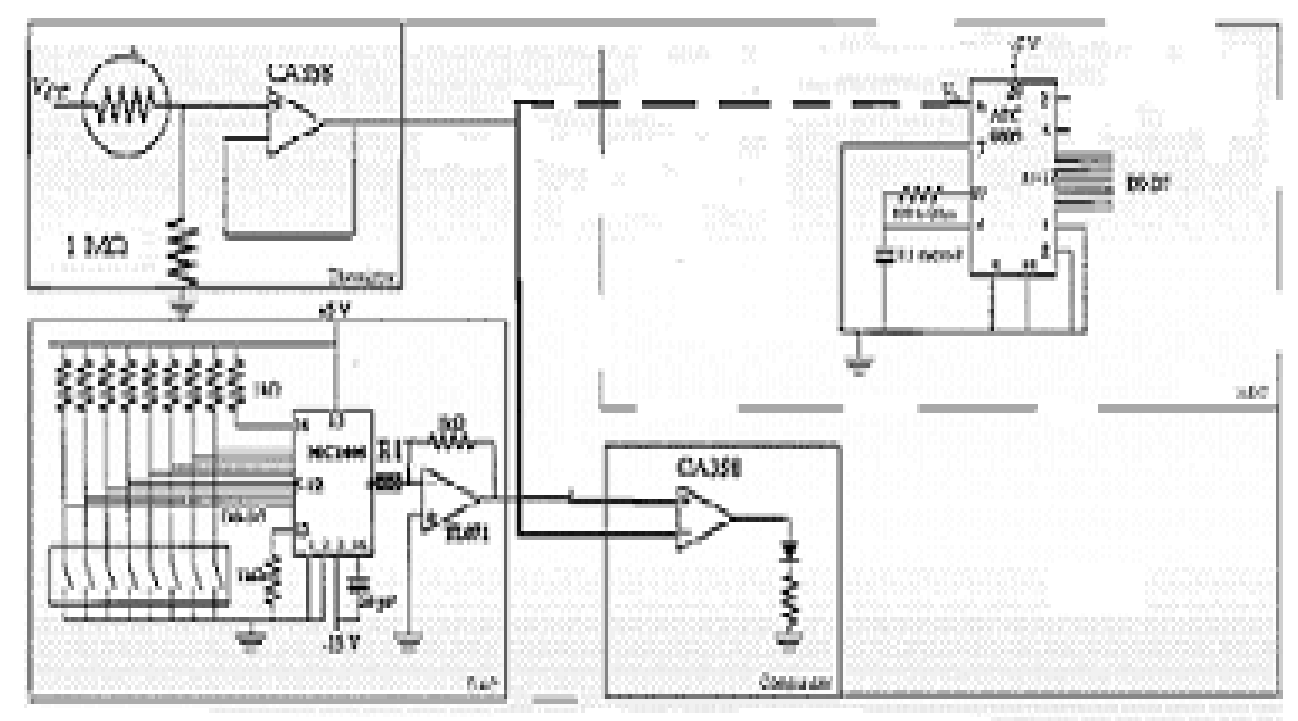

Figure (2) Electronic Circuit Diagram

The Dornier medilas fiberton Nd:YAG system, was used in this work as main source of laser power, the used out put power was between $2 \mathrm{w}$ up to $35 \mathrm{~W}$, CW mode for10S exposure time.

\section{Testing procedure}


مجلة العلوم الهندسية- العدد الثالث- 2008

According to the material mixing ratios, the fabricated thermistors are classified into three groups as shown in table (2), each group with two samples:

Table (2): The Thermistor Groups

\begin{tabular}{|l|l|l|l|l|l|l|}
\hline $\begin{array}{l}\text { Group } \\
\text { NO. }\end{array}$ & $\begin{array}{l}\mathrm{Mn}_{3} \mathrm{O}_{4} \\
\%\end{array}$ & $\begin{array}{l}\mathrm{Fe}_{2} \mathrm{O}_{3} \\
\%\end{array}$ & $\begin{array}{l}\mathrm{Al}_{2} \mathrm{O}_{3} \\
\%\end{array}$ & $\begin{array}{l}\mathrm{TiO}_{2} \\
\%\end{array}$ & $\begin{array}{l}\mathrm{ZnO} \\
\%\end{array}$ & $\begin{array}{l}\text { Temperature } \\
\mathbf{0}\end{array}$ \\
\hline One & 65 & 3 & 12 & 12 & 8 & 1000 \\
& 65 & 3 & 5 & 19 & 8 & 1150 \\
\hline Two & 65 & 3 & 5 & 12 & 15 & 1000 \\
\hline Three & 65 & & & & & 1150 \\
\hline
\end{tabular}

The electrical output voltage of the detector to the input radiation laser power has been measured, evaluated and discussed due to the materials ratios in each group, with two fabrication temperatures.

\subsection{Group one}

In this group, two samples had been studied with different fabrication temperatures as mentioned before, each sample with different resistance value.

The detector responsivity was calculated from the output voltage measured for all fabricated detectors in this group. Figure (3) shows the group one output voltage as a function of incident $\mathrm{Nd}: \mathrm{YAG}$ laser power.

For group one, the sample with $1000{ }^{\circ} \mathrm{C}$ responded to laser power at $2 \mathrm{~W}$ up to $20 \mathrm{~W}$, the output voltage was 0.01 to $1.24 \mathrm{~V}$ respectively, the relation is linear. For the same level of laser power the output voltage of sample fabricated with $1150^{\circ} \mathrm{C}$ was started from $0.16 \mathrm{~V}$ to $1.73 \mathrm{~V}$, respectively, the relation is linear; also responsivity of the sample with $1150{ }^{\circ} \mathrm{C}$ was better than the sample with $1000{ }^{\circ} \mathrm{C}$. 
The responsivity of sample with $1150{ }^{\circ} \mathrm{C}$ is $0.085(\mathrm{~V} / \mathrm{W})$, and the responsivity of sample with $1000{ }^{\circ} \mathrm{C}$ was found to be $0.066(\mathrm{~V} / \mathrm{W})$.

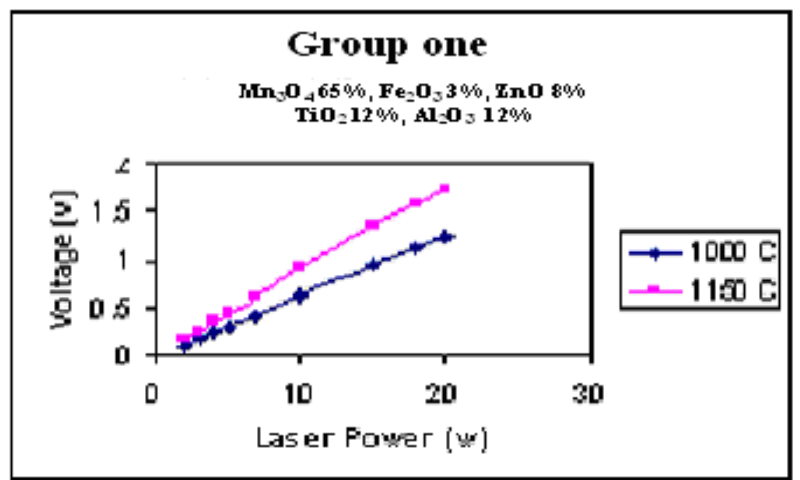

\section{Figure (3): The Output Voltage Gained from Irradiation of Group (1) as Function of Laser Power}

\subsection{Group two}

The $\mathrm{TiO}_{2}$, that was used in thermistor fabrication for this group, has a crystal structure as diatom positive ion oxide. Contribution of this material to the detector responsivity was studied for the fabrication temperatures, $1000{ }^{\circ} \mathrm{C}$ and $1150^{\circ} \mathrm{C}$. Figure (4) shows the group two output voltages as a function of incident laser power.

For group two, the sample with $1000{ }^{\circ} \mathrm{C}$ was responded to laser power at 2 $-20 \mathrm{~W}$, the output voltage was $0.006 \mathrm{~V}$ to $0.064 \mathrm{~V}$, respectively, the relation is linear. For the sample with $1150{ }^{\circ} \mathrm{C}$ and for laser power started from $2 \mathrm{~W}$ and extended to $32 \mathrm{~W}$ the output voltage was $0 \mathrm{~V}$ to $0.09 \mathrm{~V}$ respectively. The detector started to response to the laser power above $10 \mathrm{~W}$, the relation is also linear.

The responsivity of this group was very low compared to group one, although the responsivity of group two was low, sample with $1150{ }^{\circ} \mathrm{C}$ fabrication temperature showed responsivity about $0.002(\mathrm{~V} / \mathrm{W})$, while sample with $1000{ }^{\circ} \mathrm{C}$ fabrication temperature has responsivity about $0.003(\mathrm{~V} / \mathrm{W})$. From these results one can conclude that increasing of $\mathrm{TiO}_{2}$ ratio has negative effect in thermistor 
مجلة العلوم الهندسية- العدد الثالث- 2008

responsivity, but it showed rapid increasing in responsivity above $10 \mathrm{~W}$ input laser power.

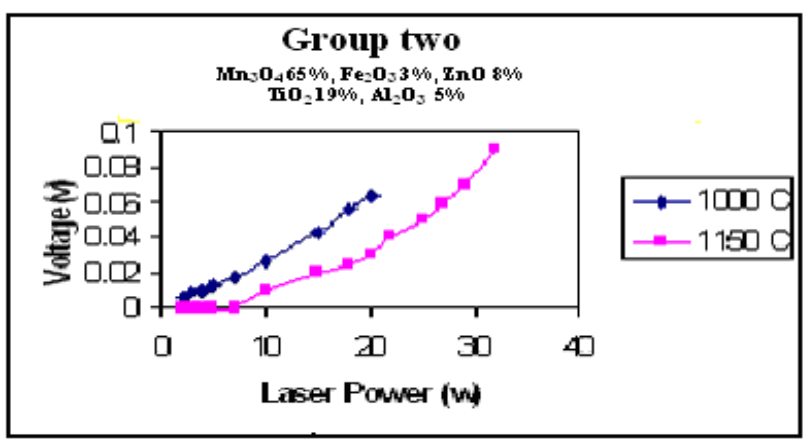

Figure (4): The output voltage gained from irradiation of group

(2) as a function of laser power.

\subsection{Group three}

$\mathrm{ZnO}$, that was used in thermistor fabricated in this group, has a crystal structure as diatom positive ion oxide, contribution of this material to the detector responsivity was studied for fabrication temperatures $1000^{\circ} \mathrm{C}$ and $1150^{\circ} \mathrm{C}$. Figure (5) shows the group three output voltage as a function of incident laser power.

For group three, when the $\mathrm{ZnO}$ was $15 \%$, sample with $1000{ }^{\circ} \mathrm{C}$ was responded to laser power starting from $2-20 \mathrm{~W}$, the output voltage was $0.036 \mathrm{~V}$ to $0.538 \mathrm{~V}$ respectively, the relation is linear. Sample with $1150^{\circ} \mathrm{C}$, for the same level of laser power, gave output voltage $0.036 \mathrm{~V}$ to $0.603 \mathrm{~V}$, respectively. The relation is linear, also.

Both samples showed better responsivity than group two but group three was less responsivity than group one, sample with $1150^{\circ} \mathrm{C}$ fabrication temperature showed higher responsivity, about $0.033(\mathrm{~V} / \mathrm{W})$, and sample with $1000^{\circ} \mathrm{C}$ fabrication temperature has responsivity about $0.025(\mathrm{~V} / \mathrm{W})$. 
From these results one can conclude that increasing of $\mathrm{ZnO}$ percentage has positive effect in thermistor responsivity, but less than the effect of increasing $\mathrm{Al}_{2} \mathrm{O}_{3}$ percentage.

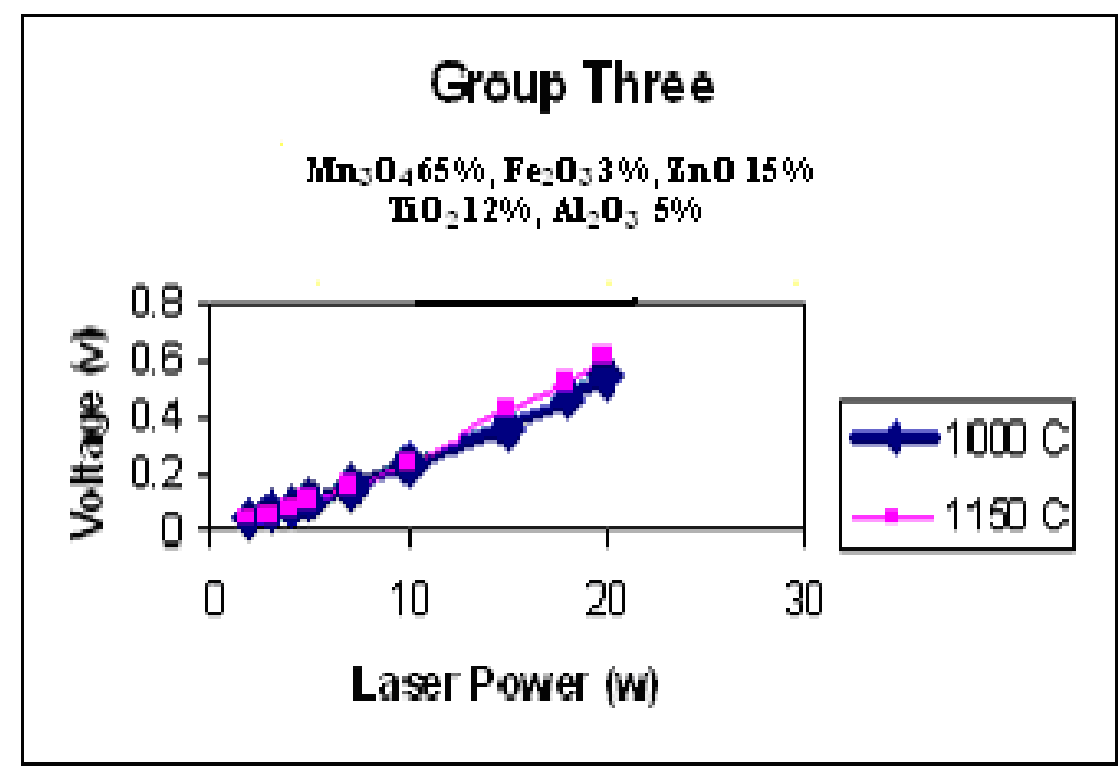

Figure (5): The output voltage gained from irradiation of group (3) as function of laser power

From the above results, the responsivity of each sample in the three groups was calculated. From the obtained curves, table (3) shows the calculated responsivity for each sample.

From this table one can concludes that the increasing of fabrication temperature enhance the responsivity for groups one and three, for group two the responsivity was degraded which means that the high temperature has negative effect in group two. 
مجلة العلوم الهندسية- العدد الثالث- 2008

Table (3) groups Responsivity

\begin{tabular}{|l|l|l|l|l|}
\hline \multirow{2}{*}{$\begin{array}{l}\text { Group } \\
\text { number }\end{array}$} & \multicolumn{3}{|c|}{ Responsivity (V/W) } \\
\cline { 2 - 5 } & 1000 ' C & $\begin{array}{l}\text { Thermistor } \\
\text { Resistance } \\
(\mathrm{M} \Omega)\end{array}$ & 1150 ' C & $\begin{array}{l}\text { Thermistor } \\
\text { Resistance } \\
(\mathrm{M} \Omega)\end{array}$ \\
\hline One & 0.066 & 1.7 & 0.085 & 1.9 \\
\hline Two & 0.003 & 3.2 & 0.002 & $>88$ \\
\hline Three & 0.025 & 1.6 & 0.033 & 3.6 \\
\hline
\end{tabular}

In group one, the $\mathrm{Al}_{2} \mathrm{O}_{3}$ was $12 \%$, but in the other groups it was $5 \%$. This means that group one has the higher ratio of $\mathrm{Al}_{2} \mathrm{O}_{3}$ from these results one can conclude that increasing of $\mathrm{Al}_{2} \mathrm{O}_{3}$ ratio has positive effect in thermistor responsivity, This can be attributed to the fact that this metal is trivalent positive ion and prove the NTC thermistor mechanism. Comparing between the three groups, we found that group one had the highest voltage output with fabricated temperature $1150^{\circ} \mathrm{C}$ and hence highest responsivity, group two had the lowest output voltage and hence the lowest responsivity at same fabricated temperature, group three had moderate output voltage and responsivity due to increasing of $\mathrm{ZnO}$ percentage. 


\section{Conclusions}

From the previous analyses, and referring to the responsivity table, one can conclude the followings:-

1- Thermistor responsivity is improved with increasing $A l_{2} O_{3}$ percentage.

2- Thermistor responsivity is improved with increasing $\mathrm{ZnO}$ percentage, but less than $\mathrm{Al}_{2} \mathrm{O}_{3}$.

3- Thermistor responsivity is degraded with increasing $\mathrm{TiO}_{2}$ percentage above $12 \%$, and responsivity is degraded much less with $1150{ }^{\circ} \mathrm{C}$ fabrication temperature.

4- The best thermiators fabrication temperature is $1150^{\circ} \mathrm{C}$.

\section{References}

[1] A.ROGALSKI, "INFRARED DETECTORS," - Military University of technology-Warsaw-Poland- 2000.

[2] Han Singh Halwa, "PHOTONDETECORS AND FIBER OPTICS," - los angeles - USA-2001.

[3] J.D Vincent, "FUNDAMENTALS OF INFRARED DETECTOR OPERATION AND TESTING," - New York 1990.

[4] S.M Ryvkin, "PHOTOELECTRIC EFFECTS IN SEMICONDUCTORS," consultant's bureau, New York, 1964.

[5] Silvano Donati, "PHOTODETECTOR DEVICES, CIRCUITS AND APPLICATIONS," - University of pavia.

[6] E.D.Macklen, "THERMISTORS," -Glasgow, Scotland, electrochemical publications, 1979.

[7] S.T.Kshirsager, "ELECTRICAL AND CRYATALLOGRAHPIC STUDIES," J.PHYS. SOC. Japan- 1969.

[8] P. Vicenzini, "CHEMICAL PREPARATION OF NTC THERMISTORS WITH LOW RESISTVITY AND HIGH STABILITY,” - Amsterdam, Elsevier 1987. 
مجلة العلوم الهندسية- العدد الثالث- 2008

[9] J.A. WISE, "STABILITY OF GLASS-ENCAPSULATED DISC - TYPE THERMISTOR," - 1992.

[10] S.D. WOOD, “AN INVESTIGATION OF THE STABILITY OF THERMISTORS," - 1978.

[11] Laser-Medizin, "APPLICATION HANDBOOK MEDILAS E," Zentrum Gmbh - 12207 Berlin - Germany.

[12] P.L. Richards, “ADVANCED FAR-INFRARED DETECTORS," Infrared Phys-TECHNOL. 35, 127-146(1994). 